IZA DP No. 4420

Understanding Compulsory Schooling Legislation:

A Formal Model and Implications for Empirical Analysis

Mark Gradstein

Moshe J ustman

September 2009 


\title{
Understanding Compulsory Schooling Legislation: A Formal Model and Implications for Empirical Analysis
}

\author{
Mark Gradstein \\ Ben Gurion University \\ and IZA
}

Moshe Justman

Ben Gurion University

\section{Discussion Paper No. 4420 \\ September 2009}

\author{
IZA \\ P.O. Box 7240 \\ 53072 Bonn \\ Germany \\ Phone: +49-228-3894-0 \\ Fax: +49-228-3894-180 \\ E-mail: iza@iza.org
}

Any opinions expressed here are those of the author(s) and not those of IZA. Research published in this series may include views on policy, but the institute itself takes no institutional policy positions.

The Institute for the Study of Labor (IZA) in Bonn is a local and virtual international research center and a place of communication between science, politics and business. IZA is an independent nonprofit organization supported by Deutsche Post Foundation. The center is associated with the University of Bonn and offers a stimulating research environment through its international network, workshops and conferences, data service, project support, research visits and doctoral program. IZA engages in (i) original and internationally competitive research in all fields of labor economics, (ii) development of policy concepts, and (iii) dissemination of research results and concepts to the interested public.

IZA Discussion Papers often represent preliminary work and are circulated to encourage discussion. Citation of such a paper should account for its provisional character. A revised version may be available directly from the author. 
IZA Discussion Paper No. 4420

September 2009

\section{ABSTRACT}

\section{Understanding Compulsory Schooling Legislation: A Formal Model and Implications for Empirical Analysis}

We construct a simple model of compulsory schooling in which legislation and compliance are endogenously determined by individuals disciplined by social norms, optimizing their voting decisions and the school attendance of their children. The model provides a formal framework for interpreting empirical results on the effect of compulsory-schooling legislation (CSL) on enrollment. This sheds light on the use of CSL as an instrumental variable to identify the benefits of schooling, suggesting how the estimates it produces may be biased.

JEL Classification: $\quad 121$

Keywords: education, compulsory schooling, compliance norms

Corresponding author:

Mark Gradstein

Department of Economics

Ben-Gurion University of the Negev

P.O. Box 653

Beer-Sheva 84105, Israel

Israel

E-mail: grade@bgu.ac.il 


\section{Introduction}

There is increased interest in compulsory-schooling legislation (CSL) as an instrument for identifying the benefits of schooling. ${ }^{1}$ Studies in this vein see it as causing an exogenous increase in schooling among those who would otherwise have dropped out at an earlier age: a treatment effect, interpretation of which does not require a behavioral model. However, substantial evidence of the weak effect of CSL on enrollment, described below, and the obviously endogenous nature of both legislation and enrollment, suggest that a formal framework may help untangle these effects and allow a clearer understanding of the empirical evidence. The purpose of this paper is to construct such a model, which endogenizes compulsory schooling legislation and compliance, and consider its implications for empirical analysis.

Empirical studies on the effect of compulsory-schooling legislation on enrollment, though far from uniform in their findings, have generally failed to reveal the strong effects that one might expect such legislation to have, and which are implicit in its use as an instrument for schooling. West's $(1971,1978)$ careful historical analysis of education in nineteenth-century Britain is especially emphatic in its conclusion that the 1870 Education Act, which introduced compulsory education in Britain, had "negligible effect" on subsequent literacy rates (West, 1978, p. 382); and an econometric study of compulsory schooling in the United States in the 1880s by Landes and Solmon (1972) similarly failed to detect robust effects. Both studies describe an autonomous process of increased levels of education and literacy over time driven by individual motives on which legislation had no significant effect.

More recent studies of later periods_-by Oreopoulos (2006a) on Canada over most of 
the twentieth century, by Goldin and Katz (2008) on the high school movement in the United States between 1910-40, by Lleras Muney (2002) on the United States between 1920-40found legislation to have a statistically significant, though weak effect on enrollment. In Goldin and Katz's (2008, p.5) words, "the effect was modest, at best, especially in comparison with the increase in high-school enrollments and overall educational attainment."

Taken together these two sets of studies suggest that the measured effect of CSL on enrollment increased between the late nineteenth and mid-twentieth century. There are various possible explanations for this change. It could be viewed as part of a general trend towards greater compliance observed also in other fields of public policy, possibly attributable to improvements in the machinery of government as a result of technological improvements in transportation and communications, or to changes in social mores as a result of industrialization and urbanization; or it could be the consequence of extension of the franchise to lower-income households, as a result of which CSL came to be more closely aligned with the interests of the social classes whose actions it was meant to affect, so there was less motivation for truancy. ${ }^{3}$ In addition, more recent studies have had access to better data, which should allow better separation and identification of the different effects. ${ }^{4}$ Ignoring underlying trends of increased household demand for education and higher levels of compliance exaggerates the effect of CSL on enrollment. As Goldin and Katz write, "The potential endogeneity of law changes to other (unmeasured) determinants of increased schooling suggests our approach is likely to overestimate the "causal" impacts of law changes." And the same may be said of the endogeneity of compliance.

Angrist and his co-authors (Angrist and Krueger, 1991, Angrist et al., 1996, Imbens and Angrist, 1994), who pioneered the use of compulsory schooling legislation as an 
instrument to identify schooling effects from micro-data, are explicit in explaining the limitations of this approach. Borrowing their vocabulary from the medical statistics literature, they stress that CSL cannot identify the average treatment effect (ATE) of schooling on the population in general but only the local average treatment effect (LATE): its effect on those children who would not have gone to school absent CSL but who attended school following enactment of CSL. To estimate this effect there is a counter-factual that needs to be constructed, and success in this effort depends on several assumptions holding true.

Low compliance with CSL rates raises two separate issues in this regard. The first is that it renders CSL a weak instrument for identifying schooling effects. The second is the possibility of biased estimates, which may arise if compliance is correlated with unmeasured social and psychological traits that are likely to affect the benefits of schooling-say, if one were estimating the effect of schooling on the child's future earnings and the underlying mechanism driving compliance were correlated with future earnings. This might be a consequence of the way CSL changes the significance of education decisions: it is one thing not to send one's child to school beyond the required age; it is quite another to keep one's child from school in defiance of the law. Parents in the latter category are thus likely to have greater respect for the law and ability to accept authority, and if this is passed on to their children and has a generally positive effect on earnings, compliance will be positively correlated with future earnings. Under these conditions, using CSL as an instrument to identify schooling effects will overestimate the impact of schooling on earnings. ${ }^{5}$

To demonstrate these issues we construct in this paper a simple political economy model of compulsory schooling with endogenous legislation and compliance in which individuals disciplined by social norms optimize their voting decisions and the school attendance of their children. The analysis assumes that education generates an external 
benefit, which provides motivation for voters to support (some) free compulsory schooling for all. ${ }^{6}$ Truancy carries a social penalty determined by a social compliance norm, and parents must decide individually on the extent of their compliance with the legislated level of compulsory schooling. Keeping their children from school and sending them out to work increases the family's current consumption at the expense of the child's future income, as well as incurring an immediate social penalty that varies directly with the extent of the child's truancy.

The notion that the enforcement of compulsory schooling depends on social norms rather than on legal penalties reflects the practical difficulty of enforcing compulsory schooling through legal means. It is generally the very poor who keep their children from school so as to send them to work, and there is little that can be done by way of fines or incarceration that would not further harm the same children that compulsory schooling is meant to benefit. The most extreme punishment is the removal of truant children from their parents' custody, but this too may, of course, be harmful to the child, and the anguish it causes the parents may be tempered if they see it as alleviating the child's poverty. This leaves social norms as the principal means of enforcement, norms that are shaped by ingrained cultural variables and vary over time: in poorer societies the need to send one's children to work from a young age is more widespread, more easily understood, and hence more acceptable.

In equilibrium, the enrollment rate is determined by the distribution of household income and by the social penalty for truancy, and comparative-statics analysis reveals how the legislated level of compulsory schooling is affected by this social penalty and by income levels. Empirical analyses of the effect of CSL on enrollment over time that ignore the positive association of legislation with factors that positively affect schooling levels will 
produce upwardly biased estimates of the effect of legislation on enrollment, as some of the increase would have been achieved without legislation. Empirical analyses that use CSL to identify the benefits of education from individual data but ignore cross-sectional variation with factors that both increase truancy costs and are positively associated with these benefits will exaggerate the impact of education on these benefits.

The approach taken in this paper draws on two main strands of the literature. One strand, in the economics of education, addresses the effects of CSL on enrollment (Goldin and Katz, 2008; Lleras Muney, 2002; Landes and Solmon, 1972; Oreopoulos, 2006a) and employs CSL as an instrument to identify the effects of education on various outcomes (Angrist and Krueger, 1991, Angrist et al., 1996, Imbens and Angrist, 1994, Black et al., 2005, 2008; Dee, 2004, Lleras Muney, 2002, 2005; Oreopoulos, 2006b, 2008, Oreopoulos et al., 2006). The other strand, in the economics of crime, emphasizes the role of social norms in inducing legal compliance (Calvo-Armengol and Zenou, 2004; Case and Katz, 1991; Glaeser et al., 1996; Sah, 1991; Patacchini and Zenou, 2008). Incorporating the insights of this latter strand of the literature in a model of CSL contributes to a better understanding of what CSL achieves and to a clearer interpretation of its use as an instrumental variable to identify the benefits of education.

Section 2 outlines the basic model; Section 3 characterizes its equilibrium and discusses its implications; and Section 4 concludes.

\section{The Model}

Consider the following two-period model of a community with a continuum of families of measure one, each family consisting of a parent and child. Families are differentiated by their initial income $y_{i}$, the distribution of which is characterized by the cumulative distribution 
function $F$; and we assume that income is bounded from below by a minimal value $y_{L}$.

The community's democratic government determines a level of compulsory schooling, $e$, which is supplied by a public school system and funded by a poll tax of $T$ per family. We assume for simplicity that there is no free schooling beyond the compulsory level and families cannot privately "top up" public schooling. We further assume that costs are determined by the level of compulsory schooling rather than by actual attendance rates; this holds, for example, if non-compliance takes the form of partial attendance over the school year. Let $p$ denote the unit price of education, and assume a balanced government budget. Then as each household has one child and shares equally in the cost of education, we have $T$ $=p e$.

Each child is endowed with a unit of time, which the parent allocates between school attendance $h_{i}$, and work, $1-h_{i}$, where $0 \leq h_{i} \leq e$. Letting $w$ denote the wage rate for child labor, $w\left(1-h_{i}\right)$ is the family income generated by the child's work, and family consumption $c_{i}$ is equal to net income,

$$
c_{i}=y_{i}-p e+w\left(1-h_{i}\right)
$$

Parents derive utility from consumption, $c_{i}$; from their children's education, $h_{i}$ and from a positive external benefit generated by the general level of education in the child's cohort, $H$ $=\int_{i} h_{i} d i$; and they suffer a loss of utility from truancy, which is proportional to the difference $e-h_{i}$ between the mandated level of schooling and the family's chosen level of school attendance:

$$
U\left(c_{i}, h_{i}, H\right)=v\left(c_{i}\right)+h_{i}+\gamma H-k\left(e-h_{i}\right)
$$


where $v$ is an increasing concave function of consumption $\left(v^{\prime}>0, v^{\prime \prime}<0\right)$ and $\gamma$ and $k$ are positive constants. The utility loss that society imposes on those who do not comply with the law might take the form of social exclusion, a notion common in theories of crime (Akers, 1998), developed in Sah's (1991) theoretical model of crime determined by social conventions, and supported by Case and Katz's (1991) empirical evidence, which shows how both criminal and educational choices are affected by peer pressure. ${ }^{7}$ We will refer to $k$ as the community's norm of compliance. Using (1) to substitute for $c_{i}$ in (2) gives:

$$
U\left(c_{i}, h_{i}, H\right)=v\left(y_{i}-p e+w\left(1-h_{i}\right)\right)+h_{i}+\gamma H-k\left(e-h_{i}\right)
$$

We assume that parents first determine, through majority voting, the level of compulsory schooling $e$. Then each household sets its level of school attendance $h_{i}$ so as to maximize its utility given the compulsory level $e$. In voting on the compulsory level of schooling, households base their votes on their anticipation of their own choice of $h_{i}$ and on the average level of school attendance, $H$. In equilibrium, the chosen level of compulsory schooling is weakly preferred to any other level by a majority of families and the anticipated school attendance levels on which voting decisions were based conform to actual choices.

\section{Analysis}

The analysis proceeds backwards, starting with the determination of school attendance after the compulsory school level has been set. 


\subsection{School attendance}

To characterize school attendance, we take the derivative of utility (3) with respect to school attendance, $h_{i}$, to obtain the first-order condition which an optimal choice of school attendance must satisfy. At an optimal choice one of the following must hold:

Either

$$
-v^{\prime}\left(y_{i}-p e+w\left(1-h_{i}\right)\right) w+1+k=0
$$

for some attendance level $0<h_{i}<e$, which is then optimal (and family $i$ is truant); or $^{8}$

$$
-v^{\prime}\left(y_{i}-p e+w(1-e)\right) w+1+k \geq 0
$$

in which case $h_{i}=\mathrm{e}$ is optimal (and family $i$ is not truant); or

$$
-v^{\prime}\left(y_{i}-p e+w\right) w+1+k \leq 0
$$

in which case $h_{i}=0$ is optimal and the child does not attend school at all. For simplicity we exclude the third case, and assume that $-v^{\prime}\left(y_{i}-p e+w\right) w+1+k$ is always positive so that the optimal choice of $h_{i}$ is never zero. Taking the second derivative and recalling that $v^{\prime \prime}$ $<0$ by assumption, we find that the second order-condition holds throughout, and that household $i$ is truant if and only if

$$
-v^{\prime}\left(y_{i}-p e+w(1-e)\right) w+1+k<0
$$


The strict concavity of $v$ implies that $v^{\prime}$ has a well-defined inverse function, which we denote $g$ and which is decreasing. When first-order conditions hold, $g$ satisfies:

$$
\begin{aligned}
& y_{i}-p e+w\left(1-h_{i}\right)=g((1+k) / w) \text { when } h_{i}<e ; \text { and } \\
& y_{i}-p e+w(1-e) \geq \mathrm{g}((1+k) / w) \text { when } h_{i}=e .
\end{aligned}
$$

Substituting this back into the budget constraint and isolating $h_{i}$ we obtain:

$$
h_{i}=\max \left\{e,\left[y_{i}-p e+w-g((1+k) / w)\right] / w\right\}
$$

from which it follows that there is an income level $y^{*}$ above which parents fully comply with compulsory schooling laws and below which they choose some measure of truancy. It is given by:

$$
y^{*}=p e-w+g((1+k) / w)+w e
$$

The right-hand side of (8) is increasing in $e$ and decreasing in $k$, implying that:

Proposition 1: The proportion of truant families in the population increases with the level of compulsory schooling and decreases with society's compliance norm.

Aggregating individual schooling choices we obtain the average level of schooling as a function of the level of compulsory schooling $e$ and of the compliance norm $k$ : 


$$
H(e, k)=(1 / w) \int_{y_{L}}^{y^{*}}[y-p e+w-g((1+k) / w)] d F(y)+\left[1-F\left(y^{*}\right)\right] e
$$

Differentiating $H$ with respect to $e$ we have:

$$
\begin{aligned}
\partial H / \partial e & =-(1 / w) \int_{-}^{y^{*}} p d F(y)-F^{\prime}\left(y^{*}\right)(p+w) e+1-F\left(y^{*}\right)+F^{\prime}\left(y^{*}\right)(p+w) e \\
& =-(p / w) F\left(y^{*}\right)+1-F\left(y^{*}\right)
\end{aligned}
$$

Thus if most households are not truant and the cost of education is no greater than the wages of a child's labor, raising the compulsory level of schooling raises the average level of schooling. ${ }^{9}$

Taking the second differential of $H$ with respect to $e$, and using (8) to differentiate $y^{*}$, we note for future reference that $H$ is a concave function of $e$ : raising the level of compulsory schooling has a diminishing effect on the average level of schooling.

$$
\partial^{2} H / \partial e^{2}=-(1+p / w) F^{\prime}\left(\mathrm{y}^{*}\right) d y^{*} / d e=-\left[(p+w)^{2} / w\right] F^{\prime}\left(y^{*}\right) \leq 0
$$

Finally, differentiating $H$ with respect to $k$ we find that average schooling increases with the compliance norm:

$$
\partial H / \partial k=-\int_{y_{L}}^{y^{*}}\left(g^{\prime} / w\right) d F(y)+F^{\prime}\left(y^{*}\right) e g^{\prime} / w-F^{\prime}\left(y^{*}\right) e g^{\prime} / w>0
$$


as the two last terms cancel out and the derivative of $g$ is negative (it is the inverse function of $v^{\prime}$, which is decreasing). Collecting results we have:

Proposition 2: If most households are not truant and the cost of education is no greater than the wages of a child's labor, then raising the compulsory level of schooling raises the average level of schooling. The magnitude of this effect diminishes as the level of compulsory schooling rises. The average level of schooling increases with the compliance norm, $k$.

\subsection{Policy preferences}

We next characterize the community's political decision on the level of compulsory schooling $e$. Individual preferences over compulsory schooling are characterized by differentiating the utility function (3) with respect to $e$ to obtain first-order conditions, given anticipated attendance choices. There are two possibilities. The first is that the household anticipates being truant if its choice of $e$ is adopted. If this holds then applying the envelope theorem yields the first order condition:

$$
\partial U / \partial e=-p v^{\prime}\left(y_{i}-p e+w\left(1-h_{i}\right)\right)-k+\gamma \partial H / \partial e=0
$$

A solution then comprises values $e$ and $h_{i}$ that satisfy (13) and (4a). Using (4a) to substitute $(1+k) / w$ for $v^{\prime}\left(y_{i}-p e+w\left(1-h_{i}\right)\right)$ in (13), it follows that an optimal choice of $e$ in this case implies that the external benefits of the average level of schooling balance out a term that increases with the compliance norm:

$$
p(1+k) / w+k=\gamma \partial H / \partial e
$$


We assume that this is never the case, i.e., that truancy costs for the individual household are large in comparison to the external benefits of the average level of schooling (that $k$ is large in comparison to $\gamma$ ) so that no household ever prefers a level of compulsory schooling under which it will choose to be truant itself.

For a household that anticipates not being truant if its choice of $e$ is implemented, the first-order condition characterizing its optimal choice of $e$ is obtained by substituting $e$ for $h_{i}$ in (3) and differentiating $U$ with respect to $e$ :

$$
\partial U / \partial e=-(p+w) v^{\prime}\left(y_{i}-p e+w(1-e)\right)+1+\gamma \partial H / \partial e=0
$$

And the second-order condition holds as $v$ and $H$ are concave so:

$$
\partial^{2} U / \partial e^{2}=(p+w)^{2} v^{\prime \prime}\left(y_{i}-p e+w(1-e)\right)+\gamma \partial^{2} H / \partial e^{2}<0
$$

Total differentiation of (15) with respect to $e$ and $y$ then yields:

$$
d e / d y=(p+w) v^{\prime \prime} / \partial^{2} U / \partial e^{2}>0
$$

The choice of $e$ is monotonically increasing in household income. This implies that preferences are single crossing (Gans and Smart, 1996), so that a political equilibrium exists and is given by the value of $e$ preferred by the median income household.

Proposition 3. If the compliance norm, $k$, is large in comparison to the marginal external 
benefit of average schooling, $\gamma$, then a majority voting equilibrium exists in which the median income household is decisive and non-truant, and the majority of the population is non-truant. The chosen level of compulsory schooling is implicitly determined by (15) with $y_{i}$ equal to median income.

Denote the equilibrium choice of compulsory schooling $e^{*}$. It follows directly from our analysis that $e^{*}$ increases in median household income. To see that $e^{*}$ is also increasing in $k$ we take the total differential of (15) with respect to $e$ and $k$, obtaining

$$
d e / d y=-\left(\partial^{2} U / \partial e \partial k\right) /\left(\partial^{2} U / \partial e^{2}\right)=-\gamma\left(\partial^{2} H / \partial e \partial k\right) /\left(\partial^{2} U / \partial e^{2}\right)
$$

which has the same sign as $\partial^{2} H / \partial e \partial k$, as $\partial^{2} U / \partial e^{2}$ is negative from (16). Then differentiating $\partial H / \partial e$, given by (10), with respect to $k$, and using (8) to substitute for $y^{*}$, we obtain

$$
\partial^{2} H / \partial e \partial k=-\frac{p+w}{w} F^{\prime}\left(y^{*}\right) \frac{d y^{*}}{d k}=-\frac{p+w}{w} F^{\prime}\left(y^{*}\right) g^{\prime}\left(\frac{1+k}{w}\right) / w>0
$$

where the inequality holds because $g$ is decreasing. We thus obtain:

Proposition 4. The equilibrium compulsory schooling level $e^{*}$ is increasing in median household income and in the compliance norm $k$. 


\section{Discussion: Implications and extensions}

We consider now two implications of the model for empirical analysis. The first relates to estimates of the effect of CSL on enrollment; the second to the use of CSL as an instrument to identify the benefits of education.

\subsection{Estimating the effect of CSL on enrollment}

There are different ways of using the model to understand the effect of CSL on enrollment. The simplest, most straightforward, is to follow the model in identifying public schooling with compulsory schooling and vary its level, that is, to examine the effect of the level of compulsory schooling, $e$, on average enrollment, $H$. From (10) this effect is positive and from (19) it increases with the compliance norm $k$. Thus if there is variation in compliance norms among observations that is not accounted for in empirical estimation this may introduce a bias in the empirical estimates of the effect of compulsory schooling legislation (CSL) on actual enrollment rates. This is illustrated in Figure 1 for the case that compliance norms are stricter in more affluent societies, which also legislate higher levels of compulsory schooling. The horizontal axis is $e$, the level of CSL; the vertical axis represents the level of enrollment. Solid lines represent the effect of CSL on enrollment for a given compliance norm. The two observations $\mathrm{A}$ and $\mathrm{B}$, from different communities (or different times), are situated on different lines, the higher line corresponding to higher income and larger values of $k$ and $e$. The slope of the broken line represents the estimated effect of CSL on enrollment, and it is clearly steeper than the effect of raising the level of compulsory schooling while holding $k$ constant. This suggests that if more affluent societies typically legislate higher levels of compulsory schooling and are characterized by stricter norms of compliance with the law 
then the estimated effect of CSL on enrollment may be upwardly biased.

\section{Figures 1 and 2 about here}

A different interpretation of the effect of compulsory schooling on enrollment might consider the implication of imposing a requirement for compulsory attendance on free public schooling offered without compulsion. This would be represented in the model by a jump in $k$ when compulsion is imposed, so that sending one's child out to work instead of to school becomes a violation of the law. Then comparing enrollment between two points in time, before and after schooling becomes compulsory, provides an estimate of the effect of CSL on enrollment (Figure 2). CSL causes a jump in $k$ which causes a discontinuous rise in enrollment through two channels: the direct positive effect of $k$ on $H$, shown in equation (12) and an indirect positive effect (through the positive effect of $k$ on $e$ and the positive effect of $e$ on $H$ ), which in practice might take longer to take effect. At the same time, there are likely to be secular changes in income and social norms that cause enrollment to increase independently of the change in CSL. The possibility of separating these various effects and thus identifying the specific effect of CSL on enrollment depends on their size, on the precision and frequency with which enrollment is measured, and on the method of analysis. Empirical findings suggest that the effect of CSL on enrollment is generally not large. This might explain why studies of CSL in the nineteenth century (Landes and Solmon, 1972; West, 1978), which had access to very limited data, failed to pick up such an effect, while studies of later periods (Oreopoulos, 2006a; Goldin and Katz, 2008; Lleras Muney, 2002), which had access to much richer data were able to focus more sharply on the discontinuities of CSL and thus identify statistically significant effects. 


\subsection{Using CSL as an instrument to identify the benefits of schooling}

This in itself has implications for the use of CSL as an instrumental variable for identifying the benefits of education, as its strength as an instrument hinges on the extent in which its effect on enrollment can be sharply identified. In addition, our analysis indicates that estimates obtained in this way may be biased, if systematic variation in $k$ is correlated, say, with unobserved variables that affect the benefits of schooling (such as respect for the law); and the degree of bias increases with the extent of non-compliance (Angrist et al., 1996, Proposition 2).

More generally, as Angrist et al. (1996) emphasize, the effect that CSL identifies is the local average treatment effect (LATE) — the effect of compulsory schooling on compliers. If this is not a randomly selected group, we need to understand and be able to identify, through observable variables, the economic and social conditions that shape compliance in order to obtain economically meaningful results that can be applied in a wider context. Such a characterization could be modeled through a simple extension of the framework described in this paper, which allowed for variation across households in the marginal social penalty for non-compliance, denoted by $k$.

\subsection{Extensions}

Extensions of the model could make explicit some of the ideas raised in the preceding discussion. One set of extensions would address the endogenization of compliance norms, allowing for variation over time and across individuals, for example in the manner suggested by the literature on social interactions (Glaeser et al., 1996, Calvo-Armengol and Zenou, 2004). If parents derive disutility from their children's truancy deviating from the community 
norm, given, say, by the average degree of compliance, we could have:

$$
\delta\left[\left(e-h_{i}\right)-(\mathrm{e}-\mathrm{H})\right]=\delta\left(\mathrm{H}-h_{i}\right)
$$

as the disutility cost. It can be seen that adding this element does not qualitatively change the utility specification, so that the analysis goes through with this alternative interpretation. Glaeser et al., 1996, show that legal compliance is strongly affected by social interactions, consequently exhibiting significant variability across locations. Alternatively, one could have the shame associated with truancy increasing with income or with parental education, or with characteristics that are more difficult to observe such as religiosity or respect for the rule of law. The ability to observe the correlates of the propensity to comply are essential for controlling the bias they introduce.

Another possible direction for extending the analysis would be to allow an explicit distinction between free and compulsory schooling, as well as private schooling, either in addition to public schooling or as an alternative. These extensions raise issues of existence of a political equilibrium.

\section{Conclusion}

Compulsory schooling legislation has been the focus of many recent studies, some aimed at assessing its effect on actual schooling and some using it as an instrument to identify the effect of education on individual social and economic outcomes. These studies typically ignore the endogeneity of such legislation as well as issues of enforcement and compliance. This paper presents a simple political economy model that endogenizes both legislation and compliance. 
Analysis of the model indicates that in equilibrium both the legislated level of compulsory schooling and the actual level of schooling increase with the severity of the social penalties for non-compliance. This implies that if the severity of these penalties is correlated with other community characteristics that affect legislation-such as incomeeconometric estimates of the effect of legislation on educational attainment that do not account for variation in compliance norms may be biased. If there is a positive correlation between autonomous increases in social penalties and other community characteristics that work to raise the legislated level of compulsory schooling, such estimates are upwardly biased. The model also highlights the difficulty of separating the effect of CSL on enrollment from secular increases driven by rising incomes and changing social norms, suggesting why studies of more recent changes in CSL were more successful in identifying a significant effect on enrolment than historical studies of earlier periods.

Our analysis also has implications for the use of compulsory schooling legislation as an instrumental variable for identifying the local average treatment effect (LATE) of education, that is, the benefits of schooling for compliers with compulsory schooling legislation. It highlights the need to understand and be able to identify, through observable variables, the economic and social conditions that shape compliance, in order to interpret these estimates and apply them in a more general context. Absent such an identification, if the severity of social penalties varies systematically across households in a manner that correlates with unobservable factors that affect the future economic and social outcomes of their children, instrumental variable estimates based on CSL will be biased. 


\section{References}

Akers, Ronald L., 1998, Social Learning and Social Structure: A General Theory of Crime and Deviance, Northeastern University Press, Boston, MA.

Angrist, Joshua D., Imbens, Guido W., and Donald B. Rubin, 1996, "Identification of causal effects using instrumental variables," Journal of the American Statistical Association, 91, 444-455.

Angrist Joshua D. and Alan B. Krueger, 1991, "Does Compulsory Schooling Attendance Affect Schooling and Earnings?” Quarterly Journal of Economics, 106, 979-1014.

Black, Sandra E., Paul J. Devereux, and Kjell G. Salvanes, 2005, "Why the Apple Doesn't Fall Far: Understanding Intergenerational Transmission of Human Capital," American Economic Review, 95(1), 437-449.

Black, S.E., Devereux, P.J., and K.G. Salvanes, 2008, "Staying in the classroom and out of the maternity ward? The effect of compulsory schooling laws on teenage births," Economic Journal, 118, 1025-1054.

Calvó-Armengol, A. and Y. Zenou, 2004, "Social networks and crime decisions: The role of social structure in facilitating delinquent behavior," International Economic Review, 45, 935-954.

Case, Anne C. and Lawrence F. Katz, 1991, "The company you keep: The effects of family and neighbourhood on disadvantaged youths," NBER WP 3705.

Dee, T., 2004, “Are there Civic Returns to Education?" Journal of Public Economics 88: 1697-1720.

Devereux, Paul J. and Robert A. Hart, 2008, "Forced to Be Rich? Returns to Compulsory Schooling in Britain," IZA DP 3305. Bonn: Institute for the Study of Labor (IZA).

Edwards, Linda N., 1978, "An Empirical Analysis of Compulsory Schooling Legislation, 1940-1960," Journal of Law and Economics.

Glaeser, E.L. Sacerdote, B., and J. Scheinkman, 1996, "Crime and social interactions," Quarterly Journal of Economics, 111, 508-548.

Goldin, Claudia and Lawrence F. Katz, 2003, "Mass secondary schooling and the state: The role of state compulsion in the high school movement," mimeo, 2008.

Imbens, Guido and Joshua Angrist, 1994, "Identification and Estimation of Local Average Treatment Effects," Econometrica, 62(2), 467-476. 
Landes, William and Lewis C. Solmon, 1972, "Compulsory Schooling Legislation: An Economic Analysis of Law and Social Change in the Nineteenth Century," The Journal of Economic History, 32, 54-91.

Lleras-Muney, A., 2002, "Were Compulsory Attendance and Child Labor Laws Effective? An Analysis from 1915 to 1939," Journal of Law and Economics, 45 (2).

Lleras-Muney, A., 2005, “The Relationship Between Education and Adult Mortality in the United States," Review of Economic Studies 72, 189-221.

Oreopoulos, Philip, 2006a, “The Compelling Effects of Compulsory Schooling: Evidence from Canada," Canadian Journal of Economics, 39 (1), $22-52$.

Oreopoulos, Philip, 2006b, "Estimating Average and Local Average Treatment Effects of Education when Compulsory School Laws Really Matter," American Economic Review, 96, 152-175.

Oreopoulos, Philip, Page, Marianne, and Ann Stevens, 2006, "Does Human Capital Transfer from Parent to Child? The Intergenerational Effects of Compulsory Schooling", Journal of Labor Economics, 2006, 729-760.

Oreopoulos, Philip, 2008, "Do Dropouts Drop Out Too Soon? Wealth, Health, and Happiness from Compulsory Schooling," Journal of Public Economics.

Pattachini, Eleonora and Yves Zenou, 2008, "Juvenile crime, deterrence, and conformism," mimeo.

Sah, Raaj K., 1991, "Social osmosis and patterns of crime," Journal of Political Economy, 99, 1272-1295.

West, Edwin G., 1971, "The Interpretation of Early Nineteenth-Century Education Statistics" Economic History Review, New Series, 24 (4), 633-642.

West, Edwin G., 1978, "Literacy and the Industrial Revolution," Economic History Review, New Series, 31 (3), 369-383. 


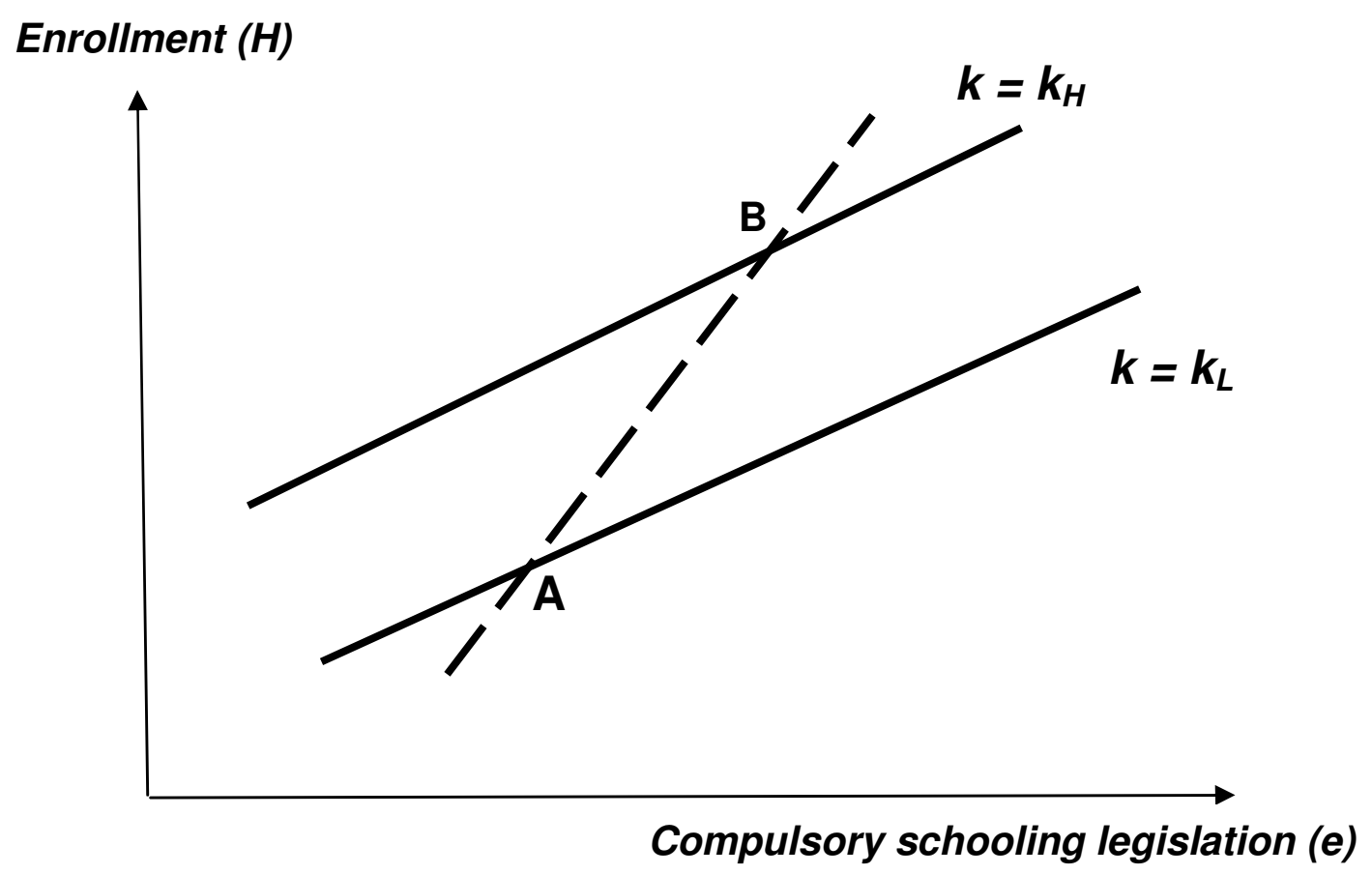

Figure 1. The effect on enrollment of variation in the level of CSL 


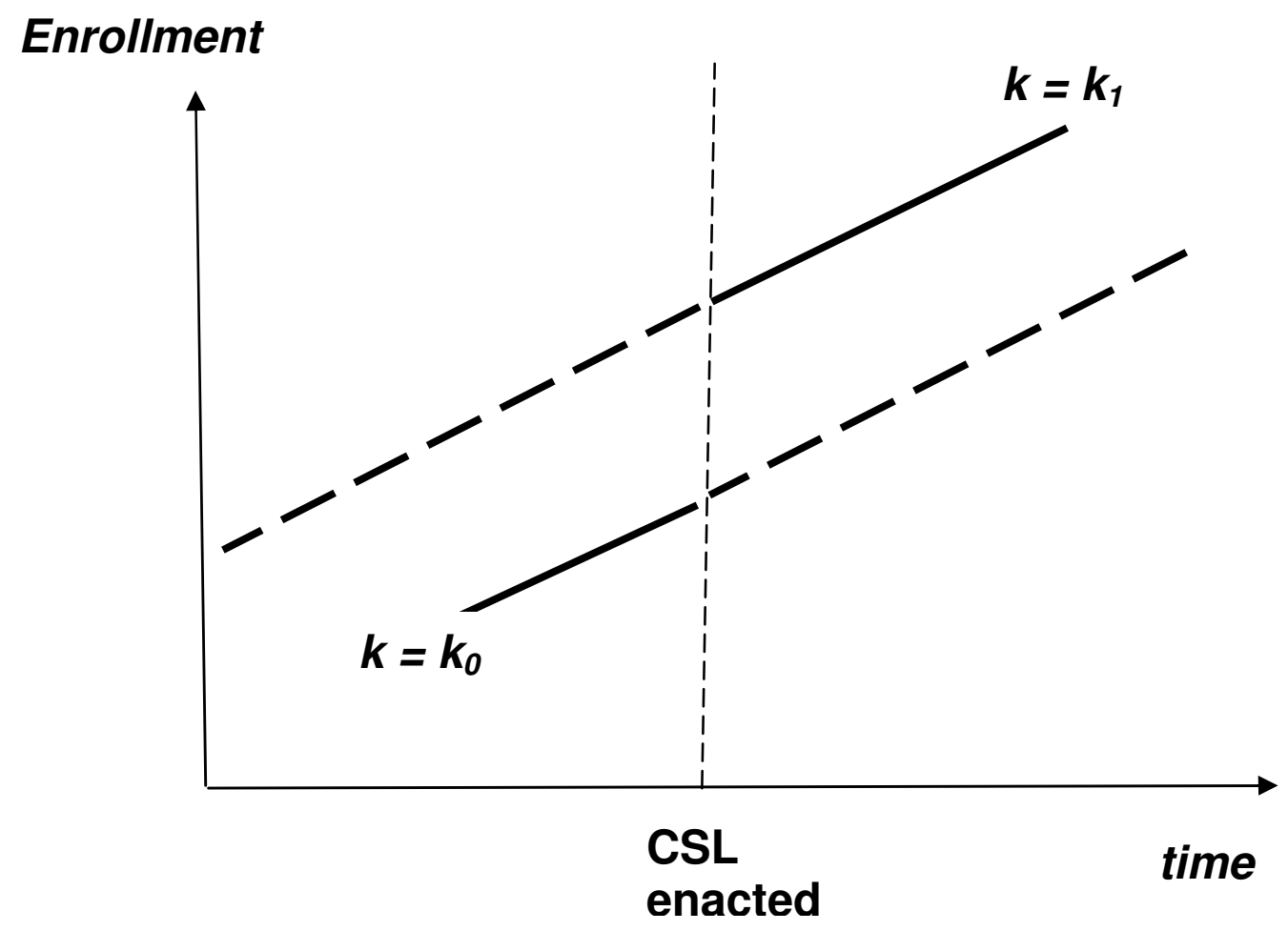

Figure 2. The effect on enrollment of enacting CSL 
${ }^{1}$ Angrist and Krueger (1991), Angrist et al. (1996), Imbens and Angrist (1994), Black et al. (2005, 2008); Dee (2004), Lleras Muney (2002, 2005), Oreopoulos (2006b, 2008), Oreopoulos (2006), among others.

2 A possible exception is the 1947 reform in Britain, enacted in 1944, which raised the school-leaving age from 14 to 15 , and which was followed by a substantial increase in enrolment in the affected age group. Interestingly, as Devereux and Hart (2008) note, "researchers have struggled to find strong effects" of the 1947 reform on a wide range of individual outcomes and their own careful study of its effect on income reaches similar conclusions. Edwards' (1978) study of the effect of compulsory schooling legislation in the United States in 1940-60 failed to find significant effects.

${ }^{3}$ Changes that increased demand for education, such as its increased economic importance, do not directly explain greater compliance as they also work to increase the extent of compulsory education. Low levels of compliance arise when the median voter wants the children of the poor to attend school more than their parents want them to attend.

${ }^{4}$ Of course, these explanations are not mutually exclusive.

${ }^{5}$ There is another related signaling effect, which we do not model, that should work in the same direction. The negative signaling effect on income of not attending schooling beyond the compulsory level should be weaker than the signaling effect of not fulfilling compulsory schooling requirements both because being raised in a household that was not law-abiding may in itself be a negative signal for future employers; and because CSL increases the fraction of children in the cohort attending school.

${ }^{6}$ Modern analyses emphasize the economic external benefits of education but earlier writings saw in the education of the poor a moral imperative and a means of promoting public order. 
${ }^{7}$ In closely related work, Patacchini and Zenou (2008) distinguish between the roles of deterrence and social pressure in inhibiting criminal behavior.

${ }^{8}$ The marginal increase in utility in reducing $h$ below $e$, which is $w v^{\prime}-k$ per unit of $h$, is less than the marginal loss of utility from the same reduction of $h$, which is 1 .

${ }^{9}$ Progressive taxation further weakens the conditions that ensure increasing compulsory schooling will raise the average schooling level. The perverse effect arises in the model as a result of regressive taxes (that place an equal burden on rich and poor) having an adverse income effect on the schooling decisions of poorer parents when compulsory schooling is extended. These parents then choose to increase truancy so as to compensate for the tax increase and consequent loss of income for consumption. When such parents are a large fraction of the population this adverse effect may outweigh the added schooling in families that are not truant in the aggregate. 